\title{
Performance Management Practices: A Decisive Approach to Improve Employee Productivity
}

\author{
Shalini Dixit ${ }^{a}$,Dr. Khushboo Sharma ${ }^{b}$ \\ ${ }^{a}$ Research Scholar, Sangam University, Bhilwara. \\ ${ }^{\mathrm{b}}$ Associate Professor, Sangam University, Bhilwara \\ ashalinidixit12@gmail.com, bkhushboosharma2010@gmail.com
}

Article History: Received: 10 November 2020; Revised 12 January 2021 Accepted: 27 January 2021; Published online: 5 April 2021

\begin{abstract}
Performance management practices include various approaches to significantly assess the organizational performance and productivity. It includes critical analysis and evaluation of employees skills and knowledge to increase output at workplace which establishes culture of proper evaluation of individual performance i.e. directly linked with attainment of individual as well as organizational goal. With the changing dimensions of business operations performance of employees is ensured through involvement of strategic approaches which enables them to understand the required standards of performance and evaluation criteria to assess productivity with merits and demerits of learning and improving better alternatives which ultimately enhances the overall performance of organization. This study helps in critical assessment of various performance management practices and its effect on employee productivity in textile firms of Bhilwara city. The performance management practices comprised of employee appraisal system, training and development, reward system and feedback which all are considered as independent variables and dependent variable is defined as employee productivity. The research paper incorporates primary data collected through a structured questionnaire from a sample size of 100 respondents who worked at various managerial levels in textile firms. A descriptive research design is used for the analysis of data with the help of mean, standard deviation and regression analysis to accomplish the research objective of assessing the effect of independent variables performance appraisal, training \& development, reward system and feedback on employee productivity. Various hypothesis are framed to test the results and draw inferences for the population. The study focuses on implementation of various approaches that can enhance employee productivity and develop a workforce through proper training and evaluation with the help of review and feedback mechanism and ensure growth of individuals as well as organization and fulfilment of organizational goals. The result is analysed through regression which helps in adoption of sustainable HR practices forced to rethink on decisions pertaining to employee productivity
\end{abstract}

Keywords: Performance management practices, employee productivity, feedback

\section{Introduction}

Performance management involves various practices that ensures organizational success through achievement of firms goals in an efficient manner and continuous improvement of firms performance to attain the best outcome. Baron and Armstrong (2007) viewed performance management as a process that involved a decisive approach that help in improving the firms productivity and employees by uplifting employee performance through teamwork and personal capabilities. Employee productivity can be viewed as efficiency of a worker to perform according to the expectations and achieve the firms goals through utilisation of proper skills and knowledge. The outcome is the result of work efficiency and concern towards achievement of business goals which are designed in line to individual goals. Performance management practices involves training and developing employees, performance evaluation and appraisal mechanism to provide a proper review and feedback system that can increase the skills and capabilities of firms employee to improve performance and maintain the high level of productivity. The strategic objective of HR department is to encourage a balanced development of practices that promotes high work performance and ensure achievement of a good environment for better chance to develop grow and promotion of high productivity which leads to organizational sustainability.

\section{Performance Management Practices}

Performance management practices are systematic ways of communicating to employees on what performance and productivity parameters are expected of them (Marsor, 2011). Jackson (2009), envisioned performance management as activities such as knowing what goals are and how they should be measured, performance evaluation, performance feedback, incentive-based performance, planning of career, motivation, training and development. The attributes involved an approach to rethink on decisions pertaining to performance enhancement and comparison of individual outcomes to the expected results. Various practices which can help in examination 
of personal performance is involved to achieve the organizational goals aligned employees goals. Appraisal provides a approach which can be used to motivate employees to focus on continuous improvement by development of strengths and overcoming weaknesses at individual level. Effective performance management practices can help organizations to implement harmonisation in conduct of responsibilities and managing the diverse workforce through poaching. Thus, training and development can contribute towards employee improvement and if it is linked with the proper evaluation system it contributes towards achievement of organizational goals. Performance feedbacks offer a reflection on past performance and motivate employees to fulfil the expectations and make an individual inclination towards objective attainment. The performance gaps are identified with the help of reliable feedback and alternative course of actions can be carried for self development of employee that aspires achievement of performance.

\section{Employee Productivity}

It is defined as the ability of workers to produce quality outputs with limited inputs (Gummesson 1998). Further studies have reflected employee productivity to be a major component that affects organizational profitability with an approach to induce performance at all levels. Organizations are concerned with long term survival and sustainable solutions can be achieved through best employees who are committed to achieve the desired goals. Thus, HR practices which involves encouragement of employees to give their best and perform in teamwork with determination and motivation can result in the key factor of productive transformation of limited inputs to high quality outputs.

\section{Review of Literature}

Okeke (2019), examined the effect of performance management on employee productivity and described the variables associated with it for implementation in large organizations.

The study was affixed with equity theory to scrutinize the extent to which the selected indicators like 360 degree feedback appraisal, evaluation review and self-assessment can refurbish performance of employees. It was revealed that some of the significant variables like 360 degree feedback appraisal and performance evaluation had drastic impact on employee productivity but self-assessment was not taken into account while enhancement of employee productivity. The paper concluded that performance management system of large organisations should be designed with holistic approach and support job description with emphasis on selfassessment mechanism of progression.

Ziyaminyana \& Pwaka (2019) studied the impact of PMS on employee productivity in IT companies by exploring the factors affecting dependent variable and to ascertain methods to improve low employee productivity.

The deduction was identification of proper management and implementation of adequate method of appraisal to motivate and increase the performance of the employees. The HR policies should be conducive to develop a culture o with proper alignment of goals at individual and organisational level to create better working relationships . training of middle level employees was vital in improving the job performance and identification of key competencies to enhance productivity and and proper reward and appreciation shoul be the driving force to certify commitment and employee productivity.

Mehmood (2017) surveyed the employees in textile sector to search solutions for better development policies and practices which can perk up the performance of employees .A linear regression model was constructed to show the interrelationship between the dependent and the independent vartiables. It is apparent that human resource development practices have a great pressure on workforce to develop efficiency . The vital indicators for the development of employees were identified and proper training methods and policies for recruitment and selection development, recognition and assessment show a considerable impact on dependent variable employee's performance.

\section{Research Objectives}

Major objective of the research is to identify the relationship between independent variables collected for the study on dependent variable. The independent variables are Performance appraisal, Training \& Development, Reward System and Feedback. Dependent variable is employee productivity.

\section{Research Design}

The descriptive research design is undertaken to collect the primary data from a sample of 80 employees working at different levels of management in selected textile firms of Bhilwara. The sample is selected through stratified random sampling and a structured questionnaire is used to collect the responses related to demographic 
and variables selected for the study. The descriptive analysis of the data is done and statistical tools like regression is applied to draw inferences. Mean, standard deviation and variance is calculated to analyse the collected data.

\section{Data Analysis}

\section{Demographic Profile}

\section{Performance Appraisals}

\section{Descriptive Statistics}

\begin{tabular}{|c|c|c|c|c|c|c|}
\hline & $\mathrm{N}$ & Minimum & Maximum & Mean & Std. Deviation & Variance \\
\hline contended & 80 & 1 & 5 & 3.00 & 2.013 & 4.051 \\
\hline company goals & 80 & 1 & 5 & 3.21 & 1.797 & 3.228 \\
\hline productivity & 80 & 1 & 5 & 3.72 & 2.013 & 3.087 \\
\hline plan & 80 & 1 & 5 & 3.46 & 1.797 & 3.228 \\
\hline work better & 80 & 1 & 5 & 3.89 & 2.013 & 3.061 \\
\hline recognition & 80 & 1 & 5 & 3.25 & 1.797 & 3.228 \\
\hline fair & 80 & 1 & 5 & 3.08 & 2.013 & 4.051 \\
\hline Valid N (listwise) & 80 & & & & & \\
\hline
\end{tabular}

Interpretation: the descriptive statistics to show the effect of performance appraisal on the dependent variable employee productivity shows the various mean values with the highest mean value for the statements performance appraisal makes me work better than expected and it enhances productivity. It has having a standard deviation of 3.061. The statement followed this was implementation of performance appraisal has a positive impact on my work productivity having a mean value 3.72and standard deviation 3.087 which interprets that employee work productivity can be increased through implementation of proper performance appraisal system and it has a positive impact on employees inclination towards better performance.

\section{Training \& Development}

Descriptive Statistics

\begin{tabular}{|c|c|c|c|c|c|c|}
\hline & $\mathrm{N}$ & Minimum & Maximum & Mean & Std. Deviation & Variance \\
\hline policy & 80 & 1 & 5 & 2.00 & 1.743 & 3.038 \\
\hline opportunities & 80 & 1 & 5 & 3.28 & 1.737 & 3.228 \\
\hline departmental & 80 & 1 & 5 & 3.00 & 2.013 & 4.051 \\
\hline creative & 80 & 1 & 5 & 3.25 & 1.797 & 3.228 \\
\hline Valid N (listwise) & 80 & & & & & \\
\hline
\end{tabular}

Interpretation: the descriptive statistics to show the effect of training \& development on the dependent variable employee productivity shows the various mean values with the highest mean value for the statements T\&D opportunities are offered to all departmental employees. It has having a standard deviation of 1.737. The statement followed this T\&D opportunities provided encourage staff to be creative having a mean value 3.25 and 
standard deviation 1.797 which interprets that employee work productivity can be increased through effective training and proper development opportunities.

\section{Rewarding System}

\section{Descriptive Statistics}

\begin{tabular}{|l|l|l|l|l|l|l|}
\hline & $N$ & Minimum & Maximum & Mean & Std. Deviation & Variance \\
\hline promotion & 80 & 1 & 3 & 1.50 & .871 & .759 \\
motivating & 80 & 1 & 5 & 3.25 & 1.797 & 3.228 \\
strategy & 80 & 1 & 5 & 3.50 & 1.669 & 2.785 \\
familiar & 80 & 1 & 5 & 2.25 & 1.650 & 2.722 \\
\hline
\end{tabular}

Interpretation: reward management is an important aspect of performance management and it has a direct impact on employees performance and efficiency towards achievement of organizational goals. Thus, proper mechanism to motivate employees in forms of financial and non financial rewards should be executed. The statements with the highest mean value 3.50 is Performance management system facilitates the implementation of strategy by attracting and retaining the right kind of people and standard deviation 1.669 followed by Performance management system facilitates implementation of strategy by motivating desired level of performance having mean value 3.25 and standard deviation 1.797 which means that proper motivation through HR strategies is required to enhance employee productivity.

\section{Performance Feedback}

\section{Descriptive Statistics}

\begin{tabular}{|l|l|l|l|l|l|l|}
\hline & $\mathrm{N}$ & $\mathrm{m}$ Minimu & Maximu & Mean & $\begin{array}{c}\text { Std. } \\
\text { Deviation }\end{array}$ & Variance \\
\hline results & 80 & 1 & 5 & 3.00 & 2.013 & 4.051 \\
feedback information & 80 & 1 & 5 & 2.75 & 1.488 & 2.215 \\
workplace & 80 & 1 & 5 & 4.00 & 1.743 & 3.038 \\
embraces & 80 & 1 & 5 & 2.25 & 1.650 & 2.722 \\
Valid N (listwise) & 80 & & & & & \\
\hline
\end{tabular}

Interpretation: the influence of performance feedback is assessed and the descriptive statistics shows that a high mean value of the statement Performance feedback has helped me to improve my productivity at workplace is 4.00 and standard deviation 1.743 gives a clear indication towards the organization feedback mechanism helps to embrace performance of employees and the second highest mean value is 3.00 for the statement Performance feedback helps me evaluate my results. Thus we can interpret that feedback is important to improve the efficiency and so proper evaluation of results should be done to enable direct improvement in focused area to enhance effectiveness and productivity. 


\section{Employee Productivity}

\section{Descriptive Statistics}

\begin{tabular}{|c|c|c|c|c|c|c|}
\hline & $\mathrm{N}$ & Minimum & Maximum & Mean & Std. Deviation & Variance \\
\hline targets & 80 & 1 & 5 & 2.00 & 1.743 & 3.038 \\
\hline time & 80 & 1 & 5 & 2.25 & 1.650 & 2.722 \\
\hline meeting & 80 & 1 & 5 & 4.00 & 1.743 & 3.038 \\
\hline deadlines & 80 & 1 & 5 & 3.25 & 1.797 & 3.228 \\
\hline cooperation & 80 & 1 & 5 & 3.00 & 2.013 & 4.051 \\
\hline concentrates & 80 & 2 & 5 & 4.25 & 1.307 & 1.709 \\
\hline efficiency & 80 & 1 & 5 & 3.00 & 2.013 & 4.051 \\
\hline output & 80 & 1 & 5 & 3.45 & 1.797 & 3.228 \\
\hline Valid N (listwise) & 80 & & & & & \\
\hline
\end{tabular}

Interpretation: the various aspects of employee productivity were assessed and the descriptive statistics show that statement related to Employee concentrates at the workplace having a high mean value of 4.25 with a standard deviation 1.307 is ranked first followed by statement related to I arrive for meetings on time having a mean value 4.00 with a standard deviation 1.743

Table: Correlations

\begin{tabular}{|l|l|l|l|l|l|l|}
\hline & & $\begin{array}{l}\text { Employee } \\
\text { Productivity }\end{array}$ & $\begin{array}{l}\text { Performance } \\
\text { Appraisal }\end{array}$ & $\begin{array}{l}\text { Training \& } \\
\text { Development }\end{array}$ & $\begin{array}{l}\text { Reward } \\
\text { System }\end{array}$ & $\begin{array}{l}\text { Performance } \\
\text { Feedback }\end{array}$ \\
\hline $\begin{array}{l}\text { Pearson } \\
\text { Correlation }\end{array}$ & $\begin{array}{l}\text { Employee } \\
\text { Productivity }\end{array}$ & 1.000 & .238 & .426 & .554 & .621 \\
\hline & $\begin{array}{l}\text { Performance } \\
\text { Appraisal }\end{array}$ & .238 & 1.000 & .336 & .547 & .432 \\
\hline & $\begin{array}{l}\text { Training \& } \\
\text { Development }\end{array}$ & .426 & .336 & 1.000 & .327 & .175 \\
\hline & $\begin{array}{l}\text { Reward } \\
\text { System }\end{array}$ & .554 & .547 & .327 & 1.000 & .624 \\
\hline & $\begin{array}{l}\text { Performance } \\
\text { Feedback }\end{array}$ & .621 & .432 & .175 & .624 & 1.000 \\
\hline
\end{tabular}

Interpretation: Correlation analysis was used to determine the association between independent and dependent variables. From the above table we can assess that employee productivity has a positive association with performance feedback and reward system where $\mathrm{R}=.624$ Performance appraisal has a high positive correlation with reward system where $\mathrm{R}=.547$. The variable of training \& development shows a high positive correlation with employee productivity which can be inferred as employee productivity enhances with proper training, feedback 
and it is seen from the values of $\mathrm{R}$ that reward system has positive association with feedback and ultimately feedback is highly correlated with productivity.

Table 4.6: Coefficient of determination

\begin{tabular}{|c|c|c|c|c|c|}
\hline Model & $\mathrm{R}$ & R Square & $\begin{array}{c}\text { Adjusted R } \\
\text { Square }\end{array}$ & $\begin{array}{c}\text { Std. Error of } \\
\text { the Estimate }\end{array}$ & $\begin{array}{c}\text { Durbin } \\
\text { Watson }\end{array}$ \\
\hline 1 & $.746^{\mathrm{a}}$ & .647 & .602 & .74710 & 2.071 \\
\hline
\end{tabular}

a. Predictors: (Constant), Performance Feedback, Performance Appraisal, Training \& Development, Reward System

b. Dependent Variable: Employee Productivity

Interpretation: The coefficient of Determination was calculated to test the fitness of model. The analysis shows that the high value of $\mathrm{R}$ square is attained which indicates that all the independent variables jointly have a significant impact on the dependent variable employee productivity by $64.7 \%$ which shows that model with respect to study variables.

Table 4.7: Analysis of variance

\begin{tabular}{|l|l|l|l|l|l|l|}
\hline Model & & Sum of Squares & Df & Mean Square & F & Sig. \\
\hline 1 & Regression & 66.532 & 4 & 305.356 & 1626.446 & $.000^{\mathrm{b}}$ \\
\hline & Residual & 14.644 & 75 & .188 & & \\
\hline & Total & & 79 & & & \\
\hline
\end{tabular}

a. Predictors: (Constant), Performance Feedback, Performance Appraisal, Training \& Development, Reward System

b. Dependent Variable: Employee Productivity

Interpretation: The analysis of variance is calculated to check the significance of the model and the $\mathrm{p}$ value in the above table is $.000^{\mathrm{b}}$ at $95 \%$ level of significance. Since the $\mathrm{p}$ value is less than 0.05 , the model is statistically significant and it can be inferred that employee productivity is highly dependent on all the independent variables undertaken for the research study.

\section{Findings and Conclusion}

The findings indicates that employee productivity can be enhanced through various variables like performance appraisal which makes employee proactive to perform according o the expectations and review of performance through continuous evaluation received by the feedback mechanism helps employees to focus on their performance and engage in achievement of organizational goals. Proper training \& development can be ensured if performance gap is identified between the actual and expected which can help in the accomplishment of individual as well as organizational goals. When performance is associated with reward mechanism it increases the values of achievement and staff is motivated to fulfil the expected standards of performance. The correlation between the various independent variables with the dependent variable employee productivity shows a positive association between the various indicators of accomplishment of strategic goals of the firm which embraces the need of performance assessment, proper feedback and reward as well as and continuous improvement through training opportunity, it is suggested that adequate performance feedback at workplace helps to identify the employees contribution towards achievement of goals and the need to develop employee so that they are able to manage performance and evaluate it with competencies required for understanding and attainment of individual as well as organizational goals/ the model suggested is also statistical significant which explains that employee productivity can be enhanced through the various independent variables namely performance appraisal, performance feedback, training \& development and reward system. The findings show that employee needs to be updated through feedbacks and regular appraisals keeps them motivated and ifa good performance is recognised by a proper system, it indulges employees in creative and innovative solutions to organizational issues and a positive work culture can help in anticipation of creating an employee evaluation system that directly affects 
employee productivity. Further study can be undertaken by diversifying the various independent variables to include different methods of appraisal, feedback, training \& development and the best one can be explored to be implemented or increasing employee productivity and its affect on organizational performance.

\section{References}

Chandra (2018). Impact of Performance Management System on Employee Performance- A Conceptual Framework for IT Organizations. International Journal of Civil Engineering and Technology, 9 (6), 412-420

Gandhi \& Mittar (2015). Performance Appraisal- A Step to Performance Management (Merchandisers in Indian Apparel Industry). International Journal of Scientific Progress and Research, 14 (2), 95-102

Kibichii, Kiptum \& Chege (2016). Effects of Performance Management Process on Employee Productivity: A Survey of Commercial Banks in Turkana County. IOSR Journal of Business and Management, 18 (11), 52-64

Mehmood (2017). Impact of Human resource Development Practices on Employee's Performance in textile Industry. International Journal of Academic Research and Development. 2 (6), 970-973

Okeke, Onyekwelu, Akpua \& Dunkwu (2019). Performance Management and Employee Productivity in Selected Large Organizations in South East, Nigeria. IJRDO- Journal of Business Management. 5 (3), 57-69

Owino, Oluoch \& Kimemia (2019). Influence of Performance Management Systems on Employee Productivity in County Referral Hospitals of Kiambu County. International Journal of Academic Research in Business \& Social Sciences, 9 (3), 1320-1336

Pravin \& Kishor (2016). Study of Performance Appraisal Practiced at Textile Industry in India. International Journal on Textile Engineering and Processes, 2 (1), 23-29

Samwel (2018). An Assessment of the Impact of Performance Management on Employee and Organization Performance- Evidence from Selected Private Organizations in Tanzania. International Journal of Human Resource Studies, 8 (3), 199-217

Sundaram (2017). A Study on Effectiveness of Performance Management in Textile Industry. International Journal of Multidisciplinary Research Review, V(I), 1-5

Uddin \& Rehman (2015). Performance Evaluation of Textile Industries in Bangladesh: An Empirical Study. Review of Industrial Engineering Letter, 2 (2), 10-27

Ziyaminyana \&Pwaka (2019). An Investigation into the Impact of Performance Management Systems on Employee Productivity: The Case Study of Information and Communication Technologies (ICT) Companies in Harare, Zimbabwe. European Journal of Business and Management. 11 (3), 23-40 